\title{
La lógica del don en el horizonte de la sociedad civil
}

\author{
ÁNGEL GALINDO GARCÍA \\ Pontificia Universidad de Salamanca (España) \\ agalindoga@upsa.es
}

\begin{abstract}
Resumen
En este artículo el autor analiza la encíclica Caritas in veritate de Benedicto XVI teniendo como clave de lectura el mercado, el Estado y la sociedad civil, los cuales forman una unión osmótica en la que la persona, libre y responsable, puede expresarse en términos de desarrollo integral. El mercado pasa por el contrato, el Estado por las leyes justas y la sociedad civil por el don y la gratuidad. En este contexto, la sociedad civil es esencial para no encerrar al hombre entre el mercado y el Estado.
\end{abstract}

Palabras clave: sociedad civil, lógica del don, lógica del Estado, lógica del mercado, gratuidad.

\section{The logic of the gift on the horizon of civil society}

\begin{abstract}
In this article I discuss the encyclical Caritas in veritate, Benedict XVI having as key to reading the market, the state and civil society, which form a union in which the osmotic person, free and responsible, can be expressed in terms of development. The market goes through the contract, the State by just laws and civil society for the gift and gratuity. In this context, civil society is essential to not close man between the market and the state.
\end{abstract}

Key words: civil society, logic of gift, State logic, market logic, gratuity.

Sacerdote y Catedrático de Teología Moral de la Facultad de Teología de la Universidad Pontificia de Salamanca. Rector de la misma universidad. Miembro de la Asociación Internacional EBEN sobre Ética de la empresa, asesor del Fondo ético del Banco Santander, y director de la revista de Caritas Española Corintios XIII. Entre sus abundantes publicaciones destacan los libros Moral socioeconómica (1996), Voluntariado y sociedad participativa (2004), Responsabilidad social corporativa y medios de comunicación social (2008), Caridad en la verdad. Comentario a la enciclica 'Caritas in veritate' de Benedicto XVI (2010). 
En una imagen muy querida por el Papa, el mercado, el Estado y la sociedad civil forman una unión osmótica en la que la persona, libre y responsable, puede expresarse en términos de desarrollo integral. ¿De qué manera se puede una persona comprometer para realizar el bien común según la enseñanza social de la Iglesia?

Esta cuestión de las relaciones entre mercado, Estado y sociedad civil es central en la encíclica Caritas in veritate (CV) El mercado pasa por el contrato, el Estado por las leyes justas y la sociedad civil por el don y la gratuidad. La sociedad civil es esencial para no encerrar al hombre entre el mercado y el Estado. La sociedad civil son los órganos intermedios, 'la zona intermedia' o «la personalidad de la sociedad», como decía Juan Pablo II.

Pero, más allá del elogio de la sociedad civil, lo que es más original con Benedicto XVI es que une esas tres lógicas u órdenes tomando como objetivo el bien común. Es decir, que el don y la gratuidad no se limitan a la sociedad civil, sino que deben también desarrollarse en el ámbito del mercado y en el ámbito político, es decir, introducir ahí también los espacios de gratuidad y de don, hasta el don de sí mismo.

Esto tendrá una influencia sobre todo el mundo comercial y sobre toda la política, para promover mejor el bien común ya que insertar en estos dos mundos la gratuidad, es insertar la sal que da sabor al conjunto. Una persona se puede comprometer de múltiples formas en la sociedad civil, mercantil o política, pero don y gratuidad dan un verdadero sentido y aliento a este compromiso, al colocar en el centro el amor en la verdad, que es el hilo conductor de la encíclica.

Desde este horizonte vemos conveniente, después de presentar el planteamiento de la cuestión, orientar nuestra reflexión en torno a las tres lógicas -lógica del Estado, lógica del mercado y lógica del donpara descubrir en la encíclica la importancia que el Papa da a la sociedad civil y al tercer sector viendo la urgencia de introducir en las tres lógicas la economía de gratuidad.

\section{Planteamiento de la cuestión}

Al tratar este tema lo hacemos, por tanto, desde la perspectiva de la encíclica CV de Benedicto XVI. En este documento, al analizar las tres lógicas (el mercado, el estado y el don), el Papa habla con la preocupación de seguir situando la Doctrina Social de la Iglesia (DSI) en un marco teológico y para tratar cuestiones sociales concretas de economía y de política. Para ello, responde a la pregunta: «¿cómo podemos ser realistas y prácticos, sin arrogarnos una competencia 
política que no nos compete? Podríamos decir también: se trataba del problema de una laicidad positiva, practicada e interpretada de modo correcto. «Éste es también un tema fundamental de la encíclica CV, publicada el día de San Pedro y San Pablo, que de ese modo recogió y desarrolló ulteriormente la cuestión sobre la colocación teológica y concreta de la doctrina social de la Iglesia» (Benedicto XVI, Discurso a la curia romana para el intercambio de felicitaciones con ocasión de la Navidad, 21 de diciembre de 2009). En este sentido, el Pontífice sigue la preocupación de Juan Pablo II de buscar la especificidad de la DSI (Galindo, 1996: 99145) $)^{1}$.

En el pensamiento de Benedicto XVI y en el de la DSI aparece con claridad que las tres lógicas están interrelacionadas en función de la búsqueda del bien común y de la justicia vistas desde la caridad en la verdad. «Al afrontar esta cuestión decisiva, hemos de precisar, por un lado, que la lógica del don no excluye la justicia ni se yuxtapone a ella como un añadido externo en un segundo momento y, por otro, que el desarrollo económico, social y político necesita, si quiere ser auténticamente humano, dar espacio al principio de gratuidad como expresión de fraternidad» (CV 34).

En este sentido, Benedicto XVI se mantiene fiel a León XIII quien colocaba los principios del bien común y de la justicia como fundamento y razón de ser de la DSI y, por otra parte, presenta como novedad, enraizada en la historia social cristiana (Lubich, 2007), la urgencia de introducir la economía de gratuidad en el proceso de desarrollo de las tres lógicas.

Según esto, como la historia y la praxis lo demuestran, no todas las actividades económicas responden al principio del beneficio, máxime en una época en la que el mercado no se limita a territorios bien definidos y, por tanto, a los que no llega la mediación de la política, pero sí alcanza la acción de la sociedad civil. «Hace algún tiempo, tal vez se podía confiar primero a la economía la producción de riqueza y asignar después a la política la tarea de su distribución. Hoy resulta más difícil, dado que las actividades económicas no se limitan a territorios definidos, mientras que las autoridades gubernativas siguen siendo sobre todo locales» (CV 37).

Por ello, es necesario que en el mercado, animado por el Estado y por la sociedad civil, se dé cabida a actividades económicas de sujetos que optan libremente por ejercer su tarea movidos por principios distintos al del mero beneficio, sin renunciar por ello a producir valor

Ya en el n ${ }^{\circ} 41$ de la carta encíclica Sollicitudo rei socialis (30 diciembre 1987), Juan Pablo II había afirmado que la DSI pertenecía a la teología y en concreto a la teología moral. 
económico. Es conocido cómo numerosas instituciones y movimientos religiosos y laicos han ofrecido realidades económicas en este ámbito de gratuidad. Así, podemos observar que existen, desde hace siglos, propuestas plasmadas en proyectos de desarrollo promovidas por instituciones que no buscan beneficio (Galindo, 1998; Lubich, 2007; Bruni y Zamagni, 2009). En todo caso, el proceso de globalización está haciendo que tanto el mercado como el Estado resulten insuficientes para regular las actividades económicas del ámbito internacional. Por ello, se necesitan instituciones intermedias, no basadas ni en el poder ni el beneficio, que con sus redes regulen la economía (Arroyo, 1996; Camacho, 1998; Galindo, 1999).

Asimismo, la ciencia económica nos dice que en el mundo globalizado es más difícil regular la ejecución de la justicia conmutativa, propia del mercado entre iguales, que la justicia distributiva, tarea que está en manos del poder. Por ello, mientras no se haya reorganizado una nueva forma de autoridad internacional (CV 67), es la sociedad civil, incluido el mismo mercado y las posibilidades de acción de la política con las diversas formas de economía de gratuidad, la que ha de potenciar la distribución de bienes para un desarrollo humano e integral. «En la época de la globalización, la economía refleja modelos competitivos vinculados a culturas muy diversas entre sí. El comportamiento económico y empresarial que se desprende tiene en común principalmente el respeto de la justicia conmutativa. Indudablemente, la vida económica tiene necesidad del contrato para regular las relaciones de intercambio entre valores equivalentes. Pero necesita igualmente leyes justas y formas de redistribución guiadas por la política, además de obras caracterizadas por el espiritu del don. La economía globalizada parece privilegiar la primera lógica, la del intercambio contractual, pero directa o indirectamente demuestra que necesita a las otras dos, la lógica de la política y la lógica del don sin contrapartida» (CV 37).

Para cumplir con este objetivo, la sociedad intermedia, formada entre otras por instituciones como ONGs, voluntariados, familias, asociaciones, empresas con responsabilidad social, podrá promover una nueva economía de la gratuidad.

De forma elocuente y clara nos lo dice recogiendo el pensamiento de Juan Pablo II: «En la Centesimus annus [n. 35], mi predecesor Juan Pablo II señaló esta problemática al advertir la necesidad de un sistema basado en tres instancias: el mercado, el Estado y la sociedad civil. Consideró que la sociedad civil era el ámbito más apropiado para una economía de la gratuidad y de la fraternidad, sin negarla en los otros dos ámbitos» (CV 38). 
Hoy podemos decir que la vida económica debe definirse como una realidad de múltiples y plurales dimensiones: en todas ellas, aunque en medida diferente y con modalidades específicas, debe haber respeto a la reciprocidad fraterna. De esta manera, será fiel a la esencia relacional y dinámica de la naturaleza humana, ya que, de forma especial en la época de la globalización, la actividad económica no puede prescindir de la gratuidad, que fomenta y extiende la solidaridad y la responsabilidad por la justicia y el bien común en sus diversas instancias y agentes (Galindo, 2001).

Estamos aquí ante lo que el Papa denomina 'democracia económica' donde se ha de practicar el principio de subsidiaridad haciéndonos todos responsables de todos sin dejar tal deber sólo en manos del Estado (Herr, 2009). «Se trata, en definitiva, de una forma concreta y profunda de democracia económica. La solidaridad es en primer lugar que todos se sientan responsables de todos [Sollicitudo rei socialis, 38]; por tanto no se la puede dejar solamente en manos del Estado. Mientras antes se podía pensar que lo primero era alcanzar la justicia y que la gratuidad venía después como un complemento, hoy es necesario decir que sin la gratuidad no se alcanza ni siquiera la justicia... En este caso, caridad en la verdad significa la necesidad de dar forma y organización a las iniciativas económicas que, sin renunciar al beneficio, quieren ir más allá de la lógica del intercambio de cosas equivalentes y del lucro como fin en sí mismo» (CV 38).

Siguiendo a Pablo VI, el Papa afirma que el solo objetivo del beneficio puede destruir riqueza (Martínez, 2010). Esta afirmación está confirmada por la misma ciencia económica que constata que cuando alguien invierte fuera de su contexto vital para adquirir mayor ganancia, a medio o largo plazo se empobrecerá su entorno y como consecuencia también él mismo. «La ganancia es útil si, como medio, se orienta a un fin que le dé un sentido, tanto en el modo de adquirirla como de utilizarla. El objetivo exclusivo del beneficio, cuando es obtenido mal y sin el bien común como fin último, corre el riesgo de destruir riqueza y crear pobreza. El desarrollo económico que Pablo VI deseaba era el que produjera un crecimiento real, extensible a todos y concretamente sostenible» (CV 21).

Como veremos más abajo, la lógica del don viene a prevenir algunos de los riesgos en los que suele caer el maridaje entre la lógica del mercado y la del Estado y ante la absolutización del beneficio, propio del mercado salvaje.

El Papa insiste en la relación de las causas y las soluciones de la crisis, así como las condiciones y soluciones para un desarrollo futuro. Por ello, le preocupa la gravedad de la crisis actual: «Los aspectos de la 
crisis y sus soluciones, así como la posibilidad de un nuevo desarrollo futuro, están cada vez más interrelacionados, se implican recíprocamente, requieren nuevos esfuerzos de comprensión unitaria y una nueva sintesis bumanista. Nos preocupa justamente la complejidad y gravedad de la situación económica actual, pero hemos de asumir con realismo, confianza y esperanza las nuevas responsabilidades que nos reclama la situación de un mundo que necesita una profunda renovación cultural y el redescubrimiento de valores de fondo sobre los cuales construir un futuro mejor» (CV 21).

La crisis nos obliga a revisar nuestro camino, a darnos nuevas reglas y a encontrar nuevas formas de compromiso, a apoyarnos en las experiencias positivas y a rechazar las negativas. Como consecuencia, la encíclica va a la raíz de las causas de la crisis. Estas se encuentran en la ausencia de ética en las relaciones mercantiles. Por tanto, será preciso realizar el proceso siguiente: revisar el camino actual, dar nuevas reglas al funcionamiento de la economía, encontrar nuevas formas de compromiso, apoyarnos en lo positivo... con la condición de que todo ello se realice desde un horizonte ético.

El Papa pondrá en el horizonte de su reflexión el marco de responsabilidad social. Para ello, no escatimará en referirse a lo que se denomina el «tercer sector», el cual ha de definirse junto a otros dos términos con los que se encuentran íntimamente relacionados, como hemos enunciado más arriba: el primer y segundo sector. El primero, también llamado economía de mercado, es un sector lucrativo y está formado por todas aquellas entidades cuyo fin es la búsqueda de beneficio económico y están reguladas por las leyes de la economía. El segundo, también denominado Estado, de origen keinesiano, es un sector público y por ello no lucrativo y formado por las administraciones públicas, los organismos autónomos y las empresas estatales. Su función es la de dirigir las políticas de un país para que sus ciudadanos puedan gozar de la calidad de vida adecuada. El tercer sector, muchas veces parcialmente llamado voluntariado y sindicalismo, es de iniciativa social. No es 'Estado' ni 'Mercado', aunque puede existir dentro de ellos, y está formado por todas aquellas organizaciones no lucrativas que buscan el bienestar de todos los ciudadanos. Dentro de este sector hay organizaciones tan dispares como las cooperativas agrarias tradicionales, las entidades aseguradoras, las mutualidades, organizaciones de voluntariado, fondos éticos, etc. Todo ello se concibe en la encíclica Caritas in veritate bajo la figura de la 'Lógica del don'. 


\section{La lógica del Estado}

Siguiendo la enseñanza de la DSI y de las ciencias humanas, la razón de ser del Estado es la búsqueda del bien común. La Constitución Gaudium et spes del Concilio Vaticano II, siguiendo el pensamiento de otros documentos sociales, define el bien común como aquel que «abarca el conjunto de aquellas condiciones de vida social con los cuales los hombres, las familias y las asociaciones pueden lograr con mayor plenitud y facilidad su propia perfección» (n. 74). De este concepto se deduce lo mismo que del concepto de justicia general: que ambos son responsabilidad concreta de la comunidad política, como aparece en el siguiente texto: «La actividad económica no puede resolver todos los problemas sociales ampliando sin más la lógica mercantil. Debe estar ordenada a la consecución del bien común, que es responsabilidad sobre todo de la comunidad política. Por tanto, se debe tener presente que separar la gestión económica, a la que correspondería únicamente producir riqueza, de la acción política, que tendría el papel de conseguir la justicia mediante la redistribución, es causa de graves desequilibrios» (CV 26), como es testigo la historia y como muestra el riesgo en que los poderes estatales se encuentran hoy ante una economía globalizada.

Los poderes públicos tienen un papel central en el campo de la actividad productiva, pero el Papa deja claro que no es exclusiva. Por ello, partiendo de las propuestas no cumplidas por la sociedad que aparecen en la encíclica Populorum progressio de Pablo VI, es urgente la renovación de la función de los poderes públicos: «La actividad económica y la función política se movían en gran parte dentro de los mismos confines y podían contar, por tanto, la una con la otra. La actividad productiva tenía lugar predominantemente en los ámbitos nacionales y las inversiones financieras circulaban de forma bastante limitada con el extranjero, de manera que la política de muchos estados podía fijar todavía las prioridades de la economía y, de algún modo, gobernar su curso con los instrumentos que tenía a su disposición. Por este motivo, la Populorum progressio asignó un papel central, aunque no exclusivo, a los 'poderes públicos' [Centesimus annus, 23 y 33]» (CV 25).

La sociedad civil puede prestar una gran ayuda a los poderes públicos para regular desde la lógica del don los problemas que provengan de la economía global.

La lógica del Estado tiene un sentido polivalente que ejercerá para corregir los errores que han ocasionado la crisis económica en orden a conseguir un nuevo orden económico-productivo, socialmente responsable y a medida del hombre. Este será el horizonte de actuación del Estado cuya acción ha de tener como centro al hombre, abrirse a la 
participación responsable de la sociedad civil y con el objeto de crear un nuevo orden económico y productivo (CV 41).

Hoy, en una época de globalización, el Estado tiene muchas limitaciones, dado el entramado institucional del mundo empresarial y aprendiendo la lección que se deduce la crisis económica actual para corregir sus disfunciones y errores. El poder político ha cambiado en la forma de ejercerla: ¿cuáles son sus consecuencias?, ¿cuáles las nuevas modalidades de la lógica del poder? El Papa señala algunas de estas formas nuevas: «En nuestra época, el Estado se encuentra con el deber de afrontar las limitaciones que pone a su soberanía el nuevo contexto económico-comercial y financiero internacional, caracterizado también por una creciente movilidad de los capitales financieros y los medios de producción materiales e inmateriales. Este nuevo contexto ha modificado el poder político de los estados» (CV 25).

Nos atrevemos a entresacar de la encíclica las nuevas modalidades siguientes:

- los poderes públicos del Estado se ven llamados directamente a corregir errores y disfunciones;

- parece más realista una renovada valoración de su papel y de su poder, que han de ser sabiamente reexaminados y revalorizados, de modo que sean capaces de afrontar los desafíos del mundo actual, incluso con nuevas modalidades de ejercerlos;

- con un papel mejor ponderado de los poderes públicos, es previsible que se fortalezcan las nuevas formas de participación en la política nacional e internacional que tienen lugar a través de la actuación de las organizaciones de la sociedad civil;

- en este sentido, es de desear que haya mayor atención y participación en la res publica por parte de los ciudadanos.

Este nuevo orden donde predomina la actividad socialmente responsable (Cuesta y Rodríguez, 2004; Galindo, 2004; Cuesta y Galindo, 2005) que ponga al hombre en su centro, será propuesto por los poderes o por la autoridad política en acciones concretas como las siguientes, según CV 41:

- Al igual que se pretende cultivar una iniciativa empresarial diferenciada en el ámbito mundial, también se debe promover una autoridad política repartida y que ha de actuar en diversos planos. 
- El mercado único de nuestros días no elimina el papel de los estados, más bien obliga a los gobiernos a una colaboración recíproca más estrecha.

- La sabiduría y la prudencia aconsejan no proclamar apresuradamente la desaparición del Estado. Con relación a la solución de la crisis actual, su papel parece destinado a crecer, recuperando muchas competencias.

- Hay naciones donde la construcción o reconstrucción del Estado sigue siendo un elemento clave para su desarrollo.

- La ayuda internacional, precisamente dentro de un proyecto inspirado en la solidaridad para solucionar los actuales problemas económicos, debería apoyar en primer lugar la consolidación de los sistemas constitucionales, jurídicos y administrativos en los países que todavía no gozan plenamente de estos bienes. Las ayudas económicas deberían ir acompañadas de aquellas medidas destinadas a reforzar las garantías propias de un Estado de derecho, un sistema de orden público y de prisiones, respetuoso de los derechos humanos, y a consolidar instituciones verdaderamente democráticas (Galindo, 2005a).

- No es necesario que el Estado tenga las mismas características en todos los sitios: el fortalecimiento de los sistemas constitucionales débiles puede ir acompañado perfectamente por el desarrollo de otras instancias políticas no estatales, de carácter cultural, social, territorial o religioso.

- Además, la articulación de la autoridad política en el ámbito local, nacional o internacional, es uno de los cauces privilegiados para poder orientar la globalización económica.

- Y también el modo de evitar que ésta mine de hecho los fundamentos de la democracia.

Por fin, la lógica del Estado debe estar en conexión con la lógica del mercado aunque ha de evitar uno de los riesgos de la sociedad de hoy como es la tendencia a unirse en maridaje, creando lo que se ha venido en llamar el «intervencionismo económico» que anula aquella 'democracia económica' y las tareas participativas de la sociedad civil. De ahí la importancia de distinguir cada una de las tres lógicas y ver su interrelación. El Papa lo indica con las siguientes palabras: «Cuando la lógica del mercado y la lógica del Estado se ponen de acuerdo para mantener el monopolio de sus respectivos ámbitos de influencia, se debilita a la larga la solidaridad en las relaciones entre los ciudadanos, la participación, el sentido de pertenencia y el obrar gratuitamente, que no se identifican con el 'dar para tener', propio de la lógica de la 
compraventa, ni con el 'dar por deber', propio de la lógica de las intervenciones públicas, que el Estado impone por ley... El binomio exclusivo mercado-Estado corroe la sociabilidad, mientras que las formas de economía solidaria, que encuentran su mejor terreno en la sociedad civil aunque no se reducen a ella, crean sociabilidad» (CV 39).

\section{La lógica del mercado}

El mercado no puede ser demonizado ya que se trata de un instrumento que puede ofrecer muchas ventajas y porque la actividad económica no puede reducirse a la lógica mercantil. Estas ventajas y el plus sobre la función mercantil aparece en la misma definición de Benedicto XVI: «Si hay confianza recíproca y generalizada, el mercado es la institución económica que permite el encuentro entre las personas, como agentes económicos que utilizan el contrato como norma de sus relaciones y que intercambian bienes y servicios de consumo para satisfacer sus necesidades y deseos» (CV 35). Se desprende de estas palabras que el mercado, según el Papa, es un efecto que se deriva de la dimensión antropológica del ser humano que se expresa en la capacidad de poner al servicio y a la vista de los demás sus cualidades, dones y capacidades. En este sentido, la relación del mercado con el tercer sector potencia el nivel humano de lo económico.

Asimismo, consideramos el horizonte del tercer sector desde el nivel económico. En este nivel, se quiere responder al deseo de incorporación a la vida económica de los sujetos marginales y de los excluidos o a aquellas poblaciones sobrantes que ni siquiera son dignos de explotación porque carecen de competencias convertibles en valores sociales. De aquí que se plantea una vida económica con una nueva relación con el Estado, con el derecho y con el trabajo.

Por otra parte, no es objeto de la DSI el demonizar la actividad económica; al contrario, está o es ontológicamente esencial al hombre. El ser humano es un homo economicus. En este contexto se sitúa la encíclica: «La Iglesia sostiene siempre que la actividad económica no debe considerarse antisocial. Por eso, el mercado no es ni debe convertirse en el ámbito donde el más fuerte avasalle al más débil. La sociedad no debe protegerse del mercado, pensando que su desarrollo comporta ipso facto la muerte de las relaciones auténticamente humanas» (CV 31). Efectivamente, el mal no está en el mercado en sí mismo considerado sino en el mal-uso que se ha hecho históricamente de él, especialmente a través de la orientación evolucionista que le han dado tanto el liberalismo capitalista como el capitalismo de Estado. 
Por ello, Benedicto XVI señala con claridad que el mercado no es algo perfecto, pero es una cualidad del hombre y producirá efectos positivos si su ejercicio se basa en los principios antropológicos que aparecen en la DSI: «Es verdad que el mercado puede orientarse en sentido negativo, pero no por su propia naturaleza, sino por una cierta ideología que lo guía en este sentido. No se debe olvidar que el mercado no existe en su estado puro, se adapta a las configuraciones culturales que lo concretan y condicionan... Lo que produce estas consecuencias es la razón oscurecida del hombre, no el medio en cuanto tal. Por eso, no se deben hacer reproches al medio o instrumento sino al hombre, a su conciencia moral y a su responsabilidad personal y social» (CV 31).

El mercado, según esto, es un medio o instrumento en manos del hombre que deberá utilizar siguiendo los principios éticos de la empresa regulada principalmente por la justicia conmutativa, social y distributiva con el fin de lograr la cohesión social. Ya que «el mercado está sujeto a los principios de la llamada justicia conmutativa, que regula precisamente la relación entre dar y recibir entre iguales. Pero la doctrina social de la Iglesia no ha dejado nunca de subrayar la importancia de la justicia distributiva y de la justicia social para la economía de mercado, no sólo porque está dentro de un contexto social y político más amplio, sino también por la trama de relaciones en que se desenvuelve. En efecto, si el mercado se rige únicamente por el principio de la equivalencia del valor de los bienes que se intercambian, no llega a producir la cohesión social que necesita para su buen funcionamiento. Sin formas internas de solidaridad y de confianza reciproca, el mercado no puede cumplir plenamente su propia función económica» (CV 35).

De la mano de Pablo VI, esta encíclica valorará positivamente la función del mercado en el marco del sistema económico siempre que esté guiado por los principios señalados anteriormente. Esta positiva valoración del sistema económico está propuesta en el marco de la ayuda al tercer mundo si se cumplen unas condiciones y se siguen unos objetivos. En cuanto a las condiciones señala en su primera encíclica Deus caritas est (DCE), siguiendo a Pablo VI como comentario a la encíclica Populorum progressio:

- Pablo VI subraya oportunamente en la Populorum progressio que el sistema económico mismo se habría aventajado con la práctica generalizada de la justicia, pues los primeros beneficiarios del desarrollo de los países pobres hubieran sido los países ricos (DCE 49). No se trata sólo de remediar el mal funcionamiento con las ayudas. 
- No se debe considerar a los pobres como un 'fardo' (Centesimus annus, 28), sino como una riqueza incluso desde el punto de vista estrictamente económico.

- No obstante, se ha de considerar equivocada la visión de quienes piensan que la economía de mercado tiene necesidad estructural de una cuota de pobreza y de subdesarrollo para funcionar mejor.

- Al mercado le interesa promover la emancipación, pero no puede lograrlo por sí mismo, porque no puede producir lo que está fuera de su alcance. Ha de sacar fuerzas morales de otras instancias que sean capaces de generarlas.

En cuanto a los objetivos del desarrollo en países pobres, han de partir de la necesidad de renovar los sistemas de protección y previsión ya existente desde la época de Pablo VI (CV 25). En este sentido, a estos sistemas:

- Les cuesta trabajo, y les costará todavía más en el futuro, lograr sus objetivos de verdadera justicia social dentro de un cuadro de fuerzas profundamente transformado.

- El mercado, al hacerse global, ha estimulado, sobre todo en países ricos, la búsqueda de áreas en las que emplazar la producción a bajo coste con el fin de reducir los precios de muchos bienes, aumentar el poder de adquisición y acelerar por tanto el índice de crecimiento, centrado en un mayor consumo en el propio mercado interior.

- Consiguientemente, el mercado ha estimulado nuevas formas de competencia entre los Estados con el fin de atraer centros productivos de empresas extranjeras, adoptando diversas medidas, como una fiscalidad favorable y la falta de reglamentación del mundo del trabajo.

- Estos procesos han llevado a la reducción de la red de seguridad social a cambio de la búsqueda de mayores ventajas competitivas en el mercado global, con grave peligro para los derechos de los trabajadores, para los derechos fundamentales del hombre y para la solidaridad en las tradicionales formas del Estado social.

- Los sistemas de seguridad social pueden perder la capacidad de cumplir su tarea, tanto en los países pobres, como en los emergentes, e incluso en los ya desarrollados desde hace tiempo. En este punto, las políticas de balance, con los recortes al gasto social, con frecuencia promovidos también por las instituciones financieras internacionales, pueden dejar a los ciudadanos 
impotentes ante riesgos antiguos y nuevos; dicha impotencia aumenta por la falta de protección eficaz por parte de las asociaciones de los trabajadores.

- El conjunto de los cambios sociales y económicos hace que las organizaciones sindicales tengan mayores dificultades para desarrollar su tarea de representación de los intereses de los trabajadores, también porque los gobiernos, por razones de utilidad económica, limitan a menudo las libertades sindicales o la capacidad de negociación de los sindicatos mismos.

Teniendo en cuenta estas condiciones y objetivos del mercado y el papel del Estado, el Papa en el capítulo segundo con el título «El desarrollo humano en nuestro tiempo» nos introduce de la mano de Pablo VI en la necesidad de replantear la economía y la política hacia una intervención económica de carácter social: «Pablo VI tenía una visión articulada del desarrollo. Con el término 'desarrollo' quiso indicar ante todo el objetivo de que los pueblos salieran del hambre, la miseria, las enfermedades endémicas y el analfabetismo. Desde el punto de vista económico, eso significaba su participación activa y en condiciones de igualdad en el proceso económico internacional; desde el punto de vista social, su evolución hacia sociedades solidarias y con buen nivel de formación; desde el punto de vista político, la consolidación de regímenes democráticos capaces de asegurar libertad y paz» (CV 21).

Lo referido en este texto al ámbito del desarrollo en donde el Papa sitúa la reflexión como conmemoración y comentario de la encíclica Populorum progressio, lo aplicará también a la vida política y económica del ámbito de la globalización actual, proponiendo la presencia de la lógica de la gratuidad en el centro de las dos lógicas anteriores y en la acción de la sociedad civil.

De la concepción cristiana de la persona se sigue necesariamente una justa visión de la sociedad en la que podemos ver la 'entraña del tercer sector' como base para comprender la economía de la gratuidad. Según la Rerum novarum y la DSI, la socialidad del hombre no se agota en el Estado, sino que se realiza en diversos grupos intermedios, comenzando por la familia y siguiendo por los grupos económicos, sociales, políticos y culturales los cuales, como provienen de la misma naturaleza humana, tienen su propia autonomía, sin salirse del ámbito del bien común. Es lo que la DSI llama la subjetividad de la sociedad (Centessimus annus, 49; Sollicitudo rei sociales, 15, 28). 


\section{La lógica del Don}

Debido a la importancia especial de este apartado dentro de nuestra reflexión lo dividimos en las partes siguientes: antecedentes de la gratuidad de la vida económica (Lubich, 2003; Galindo, 1998), la lógica del don en un mundo global, la lógica del don y el tercer sector y algunas características de la lógica del don en la economía del tercer sector.

\subsection{Antecedentes de la gratuidad en la vida económica}

El tema que nos ocupa impulsa a constatar que la Gratuidad de la vida económica no es una actitud nueva sino tan antigua como la existencia del ser humano. Gratuidad y egoísmo, eros y zanatos, coexisten desde que el ser humano comenzó a pecar, aunque la gratuidad precede al egoísmo ya que el hombre fue creado por, para y desde la gratuidad (Altaba et al., 2009).

Por ello, siguiendo la enseñanza de esta encíclica, comenzamos este apartado recordando algunos signos de gratuidad que ha movido la economía en el pasado para formalizar aquellas que nacen actualmente en un contexto de economía global y democrática, siguiendo las intuiciones y sugerencias de esta encíclica. En todo caso, una constatación clara nos obliga a decir que la gratuidad de la vida económica actual tiene en gran parte su origen en la trayectoria cristiana de ofrecimiento desinteresado y solidario, como la encíclica manifiesta al recordar las ofertas de los Montes de Piedad (CV 65).

Tratamos de demostrar que el 'principio de la gratuidad' puede recomponer el aparente contraste entre mercado y libertad del hombre, entre desarrollo económico y equilibrio social, subrayando la importancia de los bienes relacionales, de la fraternidad y de la comunión. El lector podrá encontrar en esta obra papal caminos para construir una sociedad participativa en el campo empresarial. Esta dimensión horizontal de la economía social se basa, como podrá verse, en la lógica del don y de la reciprocidad como búsqueda de la felicidad (CV 40-42).

Es claro que en la actualidad del siglo XXI nos encontramos con una economía en fase de transición y puesta en crisis desde la ladera de la globalización económica y financiera, pero especialmente por la caída de uno de los elementos que hasta ahora habían sido fundamentales, a nuestro juicio débiles, en la presentación de la ciencia económica moderna: la racionalidad instrumental. Su caída se manifiesta en fenómenos como el «paro laboral» y la falta de guía política en los asuntos económicos tanto de ámbito internacional como local (CV 25). 


\subsection{La lógica del don en un mundo global}

Observamos que en toda la DSI y en los ambientes positivos analizados por ella existe, según algunos autores, una necesidad de priorizar una práctica social caracterizada por la lógica del don como gratuidad, como intercambio y como derecho. Se insiste en los valores antropológicos del intercambio, de la reciprocidad en la redistribución y en la solidaridad. Como hemos visto hasta ahora:

- Hay una lógica del don dentro de la esfera social donde se activan las relaciones interpersonales y se fomentan las gratuitas. Es el cambio de los espacios vitales y comunitarios.

- Existe la lógica del intercambio ambientado por los espacios del mercado que se regula por los acuerdos y convenios. La fuerza económica está en la capacidad de iniciativa y en el incentivo que nace de la libertad. Es el mercado social del que habla Juan Pablo II.

- Aparece asimismo la lógica del derecho que tiene su origen en la potestas encargada de regular y distribuir. Aquí, la persona es concebida como ciudadano.

En la situación actual es necesario el proceso de retorno de la sociedad civil como consecuencia de la deslegitimación del Estado como árbitro y mediador único de la calidad de vida en la convivencia social. Por esto, vemos ahora dónde está el origen, la fundamentación y las características o ámbitos de la lógica del don en un mundo global.

A) Origen teológico y antropológico. El mismo título de la encíclica «La caridad en la verdad», nos indica que la lógica del don tiene a la vez una fuente teológica y otra antropológica (Dijon, 2009). Se trata en primer lugar de un don que se conoce desde la misma experiencia humana en cuanto el hombre está hecho por y para el don desde donde se vislumbra su dimensión trascendente: «La caridad en la verdad pone al hombre ante la sorprendente experiencia del don. La gratuidad está en su vida de muchas maneras, aunque frecuentemente pasa desapercibida debido a una visión de la existencia que antepone a todo a la productividad y la utilidad. El ser humano está hecho para el don, el cual manifiesta y desarrolla su dimensión trascendente» (CV 34). La aportación al don tiene origen en la misma naturaleza humana concebida en su dimensión personalista como ser en relación con la naturaleza, con los seres humanos, compañeros de camino, y con la trascendencia (Ruíz de la Peña, 1982). 
Esta característica humana de apertura a la gratuidad lo es en cuanto el hombre es imagen de Dios quien le concede este don absolutamente gratuito de manera que sobreabunda sobre el mérito: «La caridad en la verdad se nutre de ella y, al mismo tiempo, la manifiesta. Al ser un don absolutamente gratuito de Dios, irrumpe en nuestra vida como algo que no es debido, que trasciende toda ley de justicia. Por su naturaleza, el don supera el mérito, su norma es sobreabundar» (CV 34). Esta dimensión de gratuidad es signo de la presencia de Dios y de su invitación a que hagamos lo mismo, como dice el Papa citando a San Agustín (De libero arbitrio II, 8; Confesiones X, 24 y 35).

Por tanto, la lógica del don trasciende la tendencia soberbia del hombre a considerarse el autor de sí mismo, como el Papa señaló en el capítulo último sobre 'el desarrollo de los pueblos y la técnica' y con las palabras siguientes: «A veces, el hombre moderno tiene la errónea convicción de ser el único autor de sí mismo, de su vida y de la sociedad» (CV 34), y se asienta en la verdad y en el amor, como valores que sobrepasan la libertad del hombre en cuanto se le imponen y no son producidos por él. Lo mismo que el amor no nace del pensamiento o de la voluntad, sino que se impone al ser humano desde su mismo interior. Aquí nos encontramos con lo que en Moral Fundamental se denomina 'fundamentación autónoma de la moral' como concepto distinto al de la fundamentación heterónoma.

Asimismo y como consecuencia, estamos ante un don eminentemente antropológico, común a todos, cuya fuerza unificadora es la verdad y la caridad: «Al ser un don recibido por todos, la caridad en la verdad es una fuerza que funda la comunidad, unifica a los hombres de manera que no haya barreras o confines. La comunidad humana puede ser organizada por nosotros mismos, pero nunca podrá ser sólo con sus propias fuerzas una comunidad plenamente fraterna ni aspirar a superar las fronteras, o convertirse en una comunidad universal» (CV 34). La verdad y la caridad no sólo tonifican la vida de cada persona sino que configuran a la misma comunidad desde el mismo amor de Dios. La experiencia de los dos últimos siglos, con sus progresos y calamidades, nos manifiesta que sin Dios no se puede hacer humanidad, 'sin Dios, el progreso carece de aliento'.

B) Fundamentación. La lógica del don tiene, además de un origen teológico y antropológico, una fundamentación bíblica a la que se complementa con otra histórica y antropológica como señala el Papa en CV y en DCE (27ss) al hablar de la historia de la caridad. Podemos encontrar en la encíclica suficientes referencias prácticas e históricas para demostrar que la lógica del don es posible: 
$1^{\circ}$. Tenian todo en común. Después de la muerte de Cristo la primera comunidad escoge un modelo comunitario de vida en el que se vivía bajo el propósito: «tenían todo en común» (Act 2, 4-2). Con esta pobreza, vivida en fraternidad, demuestran al mundo que la fraternidad es capaz de vencer la pobreza. Forma una convivencia en la que no habrá ni pobres, ni ricos, sino una familia de hermanos en el Señor. La vida económica es fundamentalmente comunitaria, fortalecida por el 'compartir' dones, carismas y capacidades.

Se trata de un signo del Reino de Dios que anuncia un mundo nuevo. El modelo comunitario de la Iglesia primitiva no tiene valor ideológico, no es un proyecto, partido o fuerza política al lado de otros proyectos, sino un metro de base que juzga como provisional e insuficiente cualquier proyecto económico o político. Esta es su misión: declarar como insuficientes los proyectos humanos. Como el Papa Benedicto XVI señala en CV, Dios nos quiere también asociar a esa realidad de comunión: 'para que sean uno, como nosotros somos uno' (Jn 17,22). La Iglesia es signo e instrumento de esta unidad y «la Iglesia no tiene soluciones técnicas que ofrecer y no pretende mínimamente entrometerse en la política de los estados» (CV 9).

$2^{\circ}$. Cada uno aporte de lo que quiera y tenga. Pero, las respuestas generosas y políticas sociales no son exclusivas del Occidente actual. La historia de la acción social de la humanidad nos demuestra que con el cristianismo primitivo aparece la praxis de la limosna y la comunión de bienes como ayuda social extendida, convirtiéndose en una expresión de la caridad. Ahora podremos ver que las entidades no lucrativas, que van configurando tanto la imagen del tercer sector como la de la sociedad civil, tienen su antecedente en el ejercicio de la diaconía. Los primeros hospitales estructurados y los primeros silos o almacenes para recoger y repartir-repartir bienes tienen su origen en el seno de la Iglesia durante el siglo III. Ya en la época de San Agustín aparecen figuras como las hoy llamadas «sociedades intermedias» que conforman la sociedad y acercan la potestas a la autoritas (CV 48; Benedicto XVI, 2009; Galindo, 2005b).

La comunión de bienes ha sido estudiada por los Santos Padres en conexión con los tratados de limosna. La limosna nos enseña, según san Juan Crisóstomo en su Homilia 51,1 y 6, «cómo podemos llegar a ser semejantes a Dios que es la suma de todos los bienes». El Señor manda dar según lo que se pueda. San Justino, en su Apología, 67,6, se manifiesta en los siguientes términos: «el que puede y quiere, cada uno según lo que libremente determina, da lo que le parece, y lo que se recoge se entrega al presidente, el cual con lo recogido socorre a los huérfanos y viudas, a los enfermos y a otros necesitados, a los prisioneros y a los forasteros de 
paso; en una palabra, se encarga de proveer a todos los que se hallan en necesidad».

$3^{\circ}$. El siglo de la caridad. En la Edad Media se inicia la etapa denominada de beneficencia con un fundamento en la vida de caridad. La Iglesia y las órdenes religiosas fueron las máximos responsables de esta repuesta asistencial y los hospitales se convirtieron en el epicentro de la acción social. Poco a poco se va evolucionando hacia otras formas de acción social en cuanto surgen corporaciones de ayuda mutua como los gremios. De esta manera la beneficencia deja de ser un asunto exclusivamente eclesiástico. Con el humanismo, la pobreza accede al rango de problema social y surgen los primeros intentos de sistematización social. Las primeras propuestas de soluciones globales planteadas por los humanistas y reformadores sociales, se basaban en la actuación de las organizaciones gubernamentales y buscaban la solución en la trilogía población-producción-trabajo.

Tomás de Aquino situará el tema de la gratuidad de la vida económica con su reflexión sobre la propiedad de uso y de gestión así como sus propuestas en contra de la usura presentando la legitimidad de lo que hoy llamamos 'préstamos sin interés' que posteriormente desembocará durante el siglo XV en las propuestas de los Montes de Piedad a los que la encíclica hace alusión (CV 48). Los teólogos medievales fundarán este comportamiento y orientación moral de la economía desde la teología de las virtudes teologales y en lo que hoy la DSI denomina 'principios y valores'. La vida en torno al ora et labora de los monasterios configurarán un estilo de oferta gratuita de todo aquello que se produce.

Esta lógica del don, fundamentada tanto en la Sagrada Escritura como en la Tradición de la Iglesia, se desarrollará para ser auténtica bajo los principios de la DSI: amistad, sociabilidad, solidaridad, reciprocidad, confianza. Estos principios son la base de las relaciones mercantiles que se realicen bajo el principio de la gratuidad (Bruni y Zamagni, 2009). Este tipo de relaciones mercantiles gratuitas tienen un espacio en la actividad económica ordinaria como el mismo Papa señala de la forma siguiente: «La doctrina social de la Iglesia sostiene que se pueden vivir relaciones auténticamente humanas, de amistad y de sociabilidad, de solidaridad y de reciprocidad, también dentro de la actividad económica y no solamente fuera o 'después' de ella. El sector económico no es ni éticamente neutro ni inhumano o antisocial por naturaleza. Es una actividad del hombre $y$, precisamente porque es humana, debe ser articulada e institucionalizada éticamente» (CV 36).

Pero no sólo esto, el Papa insiste también en que esta dimensión económica de la gratuidad pertenece al campo de la vida económica 
ordinaria, por dos razones: en base a la exigencia del hombre actual inserto en la globalización y en base a la misma razón económica considerada en sí misma. «El gran desafío que tenemos, planteado por las dificultades del desarrollo en este tiempo de globalización y agravado por la crisis económico-financiera actual, es mostrar, tanto en el orden de las ideas como de los comportamientos, que no sólo no se pueden olvidar o debilitar los principios tradicionales de la ética social, como la transparencia, la honestidad y la responsabilidad, sino que en las relaciones mercantiles el principio de gratuidad y la lógica del don, como expresiones de fraternidad, pueden y deben tener espacio en la actividad económica ordinaria. Esto es una exigencia del hombre en el momento actual, pero también de la razón económica misma. Una exigencia de la caridad y de la verdad al mismo tiempo» (CV 36). En definitiva, debemos ser los protagonistas de la globalización, no las víctimas, procediendo racionalmente y guiados por la caridad y la verdad (Muro, 2009).

C) Características y ámbitos de la lógica del don. La lógica del don y de la gratuidad, presentada por el Papa tiene unas características concretas. Según esto, se pueden considerar tres paquetes de actividades dentro de esta lógica que marcan el compromiso social y configuran la sociedad civil: en primer lugar, las actividades propias de la llamada economía social: cooperativas, empresas de cogestión y actividades autogestionarias (Gaudium et spes, 68), inversiones socialmente responsables, microcréditos. En segundo lugar, las entidades no lucrativas con declaración de entidad públicas entre las que encontramos las mutualidades, asociaciones y sistemas fundacionales, fondos éticos (Centesimus annus, 49). Y, en tercer lugar, las actividades de colaboración social entre las que se encuentran los voluntariados, asociaciones de trabajadores y las ONGs (Quadragesimo anno, 184-186; Centesimus annus, 49).

La DSI anterior a CV insiste en las siguientes características fundamentales que están en la base y nos ayudan a entender las que Benedicto XVI nos ofrece en esta encíclica social: la relación de las diversas actividades que se derivan de la política social, con flujos y reflujos; la referencia esencial de la dimensión altruista y solidaria que define una concepción generosa de la economía; realce de la sociedad y de las instituciones intermedias por encima del poder y del Estado; la solidaridad como elemento transversal (Sollicitudo rei socialis, 41). No se trata de una solidaridad comercial, instrumental o técnica sino de una solidaridad esencial que configura las mismas estructuras económicas y cívicas. Veamos algunas propuestas por el Papa actual, contempladas en esta encíclica:

$\left.1^{a}\right)$ Las redes de solidaridad en la lógica del don. La lógica del don crea una serie de redes de solidaridad basados en los principios antes señalados. 
Estas redes han de dar respuesta a los obstáculos del mundo global y aportar nuevas sinergias tanto universal como localmente: «Las redes de solidaridad tradicionales se ven obligadas a superar mayores obstáculos. Por tanto, la invitación de la doctrina social de la Iglesia, empezando por la Rerum novarum, a dar vida a asociaciones de trabajadores para defender sus propios derechos ha de ser respetada, hoy más que ayer, dando ante todo una respuesta pronta y de altas miras a la urgencia de establecer nuevas sinergias en el ámbito internacional y local» (CV 25). Estas redes son, por tanto, manifestación de la sociedad civil a la que la DSI y CV quiere dar máxima importancia.

Entre los obstáculos más significativos a los que las redes de solidaridad responden, la encíclica señala la movilidad social, la falta de trabajo, la falta de agua, para las que son necesarias unas respuestas solidarias: «La movilidad laboral, asociada a la desregulación generalizada, ha sido un fenómeno importante, no exento de aspectos positivos porque estimula la producción de nueva riqueza y el intercambio entre culturas diferentes. Sin embargo, cuando la incertidumbre sobre las condiciones de trabajo a causa de la movilidad y la desregulación se hace endémica, surgen formas de inestabilidad psicológica, de dificultad para abrirse caminos coherentes en la vida, incluido el del matrimonio [Gaudium et spes, 63]» (CV 25; véase Alves dos Santos, 2010).

En este mismo ámbito en el que se refiere «al derecho a la alimentación y al agua tiene un papel importante para conseguir otros derechos, comenzando ante todo por el derecho primario a la vida. Por ello, según Caritas in veritate, es necesario que madure una conciencia solidaria que considere la alimentación y el acceso al agua como derechos universales de todos los seres humanos, sin distinciones ni discriminaciones》 (CV 27). $\mathrm{Si}$ las redes solidarias consiguen llegar a estos tres niveles - movilidad social, acceso al trabajo y al agua- se habrá abierto un estilo ético para la solución de la crisis, impulsada por la sociedad civil y en colaboración con el mercado y la ayuda de los poderes.

$2^{a}$ ) Lógica del don y lógica del saber. Asimismo, la lógica del don se basa en la lógica del saber que necesita la interrelación de todas funciones, entre ellas se funda en la caridad: «En esta línea, el tema del desarrollo humano integral adquiere un alcance aún más complejo: la correlación entre sus múltiples elementos exige un esfuerzo para que los diferentes ámbitos del saber bumano sean interactivos, con vistas a la promoción de un verdadero desarrollo de los pueblos (Galindo, 1992). El Papa es consciente de que en la ayuda al desarrollo no bastan los buenos sentimientos que acallan las conciencias, sino que es necesario el saber y la racionalidad para llevarlo a cabo. 
1.- La encíclica se sitúa en el estudio de los ámbitos del saber. En cuanto al alcance del saber nos dice: «con frecuencia, se cree que basta aplicar el desarrollo o las medidas socioeconómicas correspondientes mediante una actuación común. Sin embargo, este actuar común necesita ser orientado, porque 'toda acción social implica una doctrina' [Populorum progressio, 39]. Teniendo en cuenta la complejidad de los problemas, es obvio que las diferentes disciplinas deben colaborar en una interdisciplinariedad ordenada».

2.- Como se ve, la metodología del amor implica el valor de la interdisciplinariedad y el que la caridad está unida al saber: La caridad no excluye el saber, más bien lo exige, lo promueve y lo anima desde dentro. El saber nunca es sólo obra de la inteligencia [Populorum progressio, 75] sino que ha de ser sazonada por la caridad, ya que, sin el saber, el hacer es ciego (CV 30). No basta por tanto la buena voluntad para vivir en caridad ni esta ha de ser producto del sentimiento. En todo caso es necesaria la razón, la verdad y la racionalidad.

3.- En cuanto al ámbito del saber, al afrontar los fenómenos que tenemos delante, la caridad en la verdad exige ante todo conocer y entender, conscientes y respetuosos de la competencia específica de cada ámbito del saber. «La caridad no es una añadidura posterior, casi como un apéndice al trabajo ya concluido de las diferentes disciplinas, sino que dialoga con ellas desde el principio. Las exigencias del amor no contradicen las de la razón. El saber humano es insuficiente y las conclusiones de las ciencias no podrán indicar por sí solas la vía hacia el desarrollo integral del hombre» (CV 30). La caridad está presente en todo el proceso de elaboración del saber y de sus efectos.

En este orden de cosas, el ámbito del saber alcanza a la responsabilidad social en un contexto de globalización. Ante la globalización del mercado, la necesidad de la responsabilidad social de la empresa ha de ser auténtica, ya que la ética no debe ser utilizada como instrumento de marketing pues se considera como un fin expresivo del ser humano: «El mercado internacional de los capitales, en efecto, ofrece hoy una gran libertad de acción. Sin embargo, también es verdad que se está extendiendo la conciencia de la necesidad de una 'responsabilidad social' más amplia de la empresa. Aunque no todos los planteamientos éticos que guían hoy el debate sobre la responsabilidad social de la empresa son aceptables según la perspectiva de la doctrina social de la Iglesia, es cierto que se va difundiendo cada vez más la convicción según la cual la gestión de la empresa no puede tener en cuenta únicamente el interés de sus propietarios, sino también el de todos los otros sujetos que contribuyen a la vida de la empresa: trabajadores, clientes, proveedores de los diversos elementos de producción, la comunidad de referencia» (CV 40). La encíclica se abre 
aquí a la responsabilidad social y moral de todos los agentes de la empresa.

$\left.3^{a}\right)$ Sentido polivalente de la empresa en la lógica del don. Desde la lógica del don y de la gratuidad surge una manera de concebir la empresa y de comprender al empresario desde su esencialidad humana y no solo profesional originando diversos tipos de empresas: «A este respecto, es útil observar que la iniciativa empresarial tiene, y debe asumir cada vez más, un significado polivalente. El predominio persistente del binomio mercadoEstado nos ha acostumbrado a pensar exclusivamente en el empresario privado de tipo capitalista por un lado y en el directivo estatal por otro. En realidad, la iniciativa empresarial se ha de entender de modo articulado. Así lo revelan diversas motivaciones metaeconómicas. El ser empresario, antes de tener un significado profesional, tiene un significado humano [Centesimus annus, 32; Populorum progressio, 25, 27]» (CV 41). Aquí se encuentran las empresas que utilizan la pedagogía de la reciprocidad. Como consecuencia, el significado humano de este tipo de empresas, le impulsan a devolver a la sociedad lo que de ella recibieron (Ivern, 2004; Galindo, 2007a).

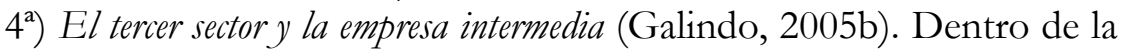
sociedad civil, un lugar significativo está ocupado, según esta encíclica, por la empresa intermedia. No se trata de la pequeña y mediana empresa (PYME), sino de una entidad con un estilo de ejercer el papel empresarial en la sociedad que considera el beneficio como un instrumento con finalidad humana y social. En esta perspectiva se sitúan las palabras del Papa: «Respecto al tema de la relación entre empresa y ética, así como de la evolución que está teniendo el sistema productivo, parece que la distinción hasta ahora más difundida entre empresas destinadas al beneficio (profit) y organizaciones sin ánimo de lucro (non profit) ya no refleja plenamente la realidad, ni es capaz de orientar eficazmente el futuro. En estos últimos decenios, ha ido surgiendo una amplia zona intermedia entre los dos tipos de empresas» (CV 46). La dimensión ética de la empresa ocupa un lugar significativo en la encíclica. El Papa lo sitúa en el marco de la zona intermedia en la que surgen multitud de empresas como las de tipo tradicional que, sin embargo, suscriben pactos de ayuda a países atrasados; por fundaciones promovidas por empresas concretas; por grupos de empresas que tienen objetivos de utilidad social; por el amplio mundo de agentes de la llamada economía civil y de comunión. No se trata sólo de un 'tercer sector', sino de una nueva y amplia realidad compuesta, que implica al sector privado y público y que no excluye el beneficio, pero lo considera instrumento para objetivos humanos y sociales (CV 46). Lo fundamental de las empresas de la 'zona intermedia' no está tanto en el reparto más o menos numeroso de los beneficios, 
sino en su «disponibilidad para concebir la ganancia como un instrumento para alcanzar objetivos de humanización del mercado y de la sociedad». De esta manera, la empresa intermedia aporta un horizonte nuevo y básico al tercer sector: su dimensión humana y social.

$\left.5^{a}\right)$ Los proyectos de desarrollo desde la lógica del don. El Papa parte del principio de que la diversidad o tipos de empresas y especial aquellas que buscan la humanización se han de potenciar incluso en los países en vías de desarrollo. Este será el camino para conseguir el auténtico desarrollo. «La potenciación de los diversos tipos de empresas y, en particular, de los que son capaces de concebir el beneficio como un instrumento para conseguir objetivos de humanización del mercado y de la sociedad, hay que llevarla a cabo incluso en países excluidos o marginados de los circuitos de la economía global, donde es muy importante proceder con proyectos de subsidiaridad convenientemente diseñados y gestionados, que tiendan a promover los derechos, pero previendo siempre que se asuman también las correspondientes responsabilidades» ( $\mathrm{CV} 47$ ). Es decir, la empresa intermedia, junto a las instituciones que forman el tercer sector, es provechosa para impulsar el proceso de ayuda al desarrollo. Junto a ello la consideración de la centralidad de la persona ocupará el horizonte principal del desarrollo. «En las iniciativas para el desarrollo debe quedar a salvo el principio de la centralidad de la persona bumana, que es quien debe asumirse en primer lugar el deber del desarrollo» (CV 47).

El Papa baja al terreno de la estrategia y habla de que los programas de desarrollo han de acomodarse al concepto del hombre como ser dinámico y dialogal $\mathrm{y}$, por ello, dirá que se ha de seguir un proceso eminentemente humano. Este proceso consiste en adaptarse a las situaciones concretas con criterios de acompañamiento y de progresión respetando el protagonismo de los afectados. «Los programas de desarrollo, para poder adaptarse a las situaciones concretas, han de ser flexibles; y las personas que se beneficien deben implicarse directamente en su planificación y convertirse en protagonistas de su realización. También es necesario aplicar los criterios de progresión y acompañamiento -incluido el seguimiento de los resultados-, porque no hay recetas universalmente válidas. Mucho depende de la gestión concreta de las intervenciones. 'Constructores de su propio desarrollo, los pueblos son los primeros responsables de él. Pero no lo realizarán en el aislamiento' [Populorum progressio, 77]... La cooperación internacional necesita personas que participen en el proceso del desarrollo económico y humano, mediante la solidaridad de la presencia, el acompañamiento, la formación y el respeto». En definitiva, el proceso de ayuda al desarrollo 
debe regirse por el principio de solidaridad y el de subsidiaridad (CV 57$58)$.

$\left.6^{a}\right)$ Lógica del don y ecología. Como consecuencia, los proyectos para un desarrollo humano integral no pueden ignorar a las generaciones sucesivas, sino que ban de caracterizarse por la solidaridad y la justicia intergeneracional, teniendo en cuenta múltiples aspectos, como el ecológico, el jurídico, el económico, el político y el cultural (CV 48; Compendio de la Doctrina Social de la Iglesia, 451-487). El camino de solución debería pasar por considerar al ser humano como centro de este problema. Para ello, teniendo en cuenta la realidad de repercusión del deterioro de la naturaleza, es necesario considerar principios de ética común a todos: es preciso la promoción del bien común, es urgente ser consciente de la responsabilidad y urgencia del cambio de modelos de producción y de consumo, no se ha de olvidar el principio de solidaridad y de subsidiaridad, de equidad intergeneracional, de justicia social y de acceso a los bienes primarios y, como Benedicto XVI ha recordado en el mensaje de la Jornada de la Paz última, «la salvaguardia de la creación exige al adopción de estilos de vida sobrios y responsables, sobre todo hacia los pobres y las generaciones futuras».

Asimismo, en CV 48 Benedicto XVI hace varias propuestas que pueden ser aceptadas por todos los hombres de buena voluntad y de culturas diversas a favor de una consideración de la naturaleza que el hombre ha de cuidar y salvaguardar. El centralismo de la persona en estas consideraciones pontificias y la necesidad de los valores éticos serán necesarios si queremos hacer un Medio Ambiente del que todos podamos gozar y cuidar. La sociedad civil deberá arrancar la solución de las garras de los poderes incontrolados e incapaces de dar una respuesta humana y ética, y deberá tener en cuenta que nunca se ha de considerar la naturaleza más importante que la persona misma.

$7^{a}$ ) Lógica del don y creación de riqueza en la ayuda al desarrollo. En la búsqueda de soluciones para la crisis económica actual, la ayuda al desarrollo de los paises pobres debe considerarse un verdadero instrumento de creación de riqueza para todos... En esta perspectiva, los Estados económicamente más desarrollados harán lo posible por destinar mayores porcentajes de su producto interior bruto para ayudas al desarrollo, respetando los compromisos que se han tomado sobre este punto en el ámbito de la comunidad internacional. Lo podrán hacer también revisando sus políticas internas de asistencia y de solidaridad social, aplicando a ellas el principio de subsidiaridad y creando sistemas de seguridad social más integrados, con la participación activa de las personas y de la sociedad civil (Centesimus annus, 22 y 29). 
De acuerdo con la DSI, recogida en el Compendio de la Doctrina Social de la Iglesia, se puede deducir del pensamiento de CV que la auténtica colaboración y cooperación sitúa la solidaridad, la justicia y la caridad (Populorum progressio, 44) como primer deber respecto a y sobre la lógica del mercado en orden a dar respuesta adecuada a las necesidades fundamentales de las personas y de los pueblos en vías de desarrollo, ya que existen elementos de la persona humana que se le deben por el hecho de ser hombre en base a su dignidad ((Centesimus annus, 34).

Asimismo, la cooperación al desarrollo ha de realizarse con la conciencia de la complejidad que trae consigo las interconexiones en el plano mundial de la globalización. Por esta razón se han de coordinar diversas iniciativas: es necesaria una programación y realizar acciones responsables, por parte de todos los componentes de la Comunidad internacional, ofreciendo a los países pobres ocasiones para su inserción en el camino de las relaciones internacionales, rompiendo barreras, concentrando intereses y recursos que colocan a tantos pueblos y países al margen de un desarrollo efectivo (Galindo, 2005a).

$\left.8^{a}\right)$ Lógica del don y la responsabilidad del ahorrador. El Papa hace alusión a las Cajas de misericordia que nacieron como lucha en contra de la usura. Si es verdad que Enrique IV en España, los reyes católicos después y diversos reyes europeos firmaron muchas cédulas y pragmáticas para sanear la agricultura y la ganadería, la industria y el comercio, también lo es que tomaron muchas medidas juntamente con la acción que nace de la renovación y reforma producida en la Iglesia europea con el impulso de los Sínodos que se celebran durante el siglo XV, para sanear las costumbres y corregir los vicios de aquella sociedad. En esta empresa de reforma los predicadores observantes desempeñaron un papel relevante con su predicación popular. Junto a los Montes de Piedad y desde ellos mismos afluyen, para responder a las necesidades, los donativos, bajo la forma de limosna o delegados, de las órdenes religiosas consagradas a la redención de cautivos, los trinitarios y los mercedarios (CV 48).

Junto a los Montes de Piedad y cajas de misericordia, con su origen en Peruggia y en Castilla, con el fin de proporcionar posibilidad de trabajo y supervivencia a aquellos que se veían imposibilitados de producir debido al peso de la usura, van naciendo en América las 'ciudades hospitales' (Galindo, 2007b). Si los primeros facilitan mediante ayudas sin interés, más gratuitos de los que hoy denominamos 'microcréditos', la posibilidad de iniciar sus empresas familiares, la segundas facilitan el que los indios puedan vivir y trabajar en comunidad adelantándose en siglos a lo que hoy llamamos 'Seguridad social' y ayudas sociales a impedidos y jubilados (CV 48). Esta sociedad intermedia, con su origen práctico y estructurado en el siglo $\mathrm{XV}$, bajo 
iniciativa tanto privada como estatal creándose la beneficencia utilitarista (Galindo, 2007b).

Ahora, en la encíclica, el Papa hace alusión al tercer sector haciendo alusión a multitud de empresas y créditos cooperativos al estilo de los Montes de piedad y microcréditos: «Si el amor es inteligente, sabe encontrar también los modos de actuar según una conveniencia previsible y justa, como muestran de manera significativa muchas experiencias en el campo del crédito cooperativo» (CV 65). Entre estas experiencias, el Papa recuerda la responsabilidad del ahorrador que, al poder convertirse en 'empresario indirecto', con palabras de Juan Pablo II en Laborem exercens, puede ejercitar su actitud de gratuidad en el interior de la lógica del mercado. La otra experiencia, señalada en la encíclica, es la de la microfinanciación que del mismo modo puede frenar la expansión de la usura y la desesperación de los países pobres.

Por eso, «tanto una regulación del sector capaz de salvaguardar a los sujetos más débiles e impedir escandalosas especulaciones, como la experimentación de nuevas formas de finanzas destinadas a favorecer proyectos de desarrollo, son experiencias positivas que se han de profundizar y alentar, reclamando la propia responsabilidad del ahorrador. También la experiencia de la microfinanciación, que hunde sus raíces en la reflexión y en la actuación de los humanistas civiles - pienso sobre todo en el origen de los Montes de Piedad-, ha de ser reforzada y actualizada, sobre todo en estos momentos en que los problemas financieros pueden resultar dramáticos para los sectores más vulnerables de la población, que deben ser protegidos de la amenaza de la usura y la desesperación» CV 65). Como se ve el papa hace una alusión a los Montes de Piedad, con el fin de ayudar a los pobres, frente a la desesperación y amenaza actual de la usura.

$\left.9^{a}\right)$ Lógica del don frente a un nuevo poder: el consumo. Hoy, la función de la empresa no termina con la producción de bienes sino que, como medio de ser fiel a los roles de la expansión y de la renovación, tiende a promover el consumo con el fin de producir más. El mercado empresarial estimula el consumo incluso impulsando el despilfarro, incluso reivindicando el 'derecho a lo superfluo', a través de la ley de la competencia, expresado en las ventas a plazos y otros medios propagandísticos. En este sentido, el Papa considera que ha nacido un nuevo poder, el de los consumidores. «La interrelación mundial ha hecho surgir un nuevo poder político, el de losconsumidores y sus asociaciones. Es un fenómeno en el que se debe profundizar, pues contiene elementos positivos que hay que fomentar, como también excesos que se han de evitar. Es bueno que las personas se den cuenta de que comprar es siempre un acto moral, y no sólo económico. El consumidor tiene una 
responsabilidad social específica, que se añade a la responsabilidad social de la empresa. Los consumidores deben ser constantemente educados [Centesimus annus, 36] para el papel que ejercen diariamente y que pueden desempeñar respetando los principios morales, sin que disminuya la racionalidad económica intrínseca en el acto de comprar. También en el campo de las compras, precisamente en momentos como los que se están viviendo, en los que el poder adquisitivo puede verse reducido y se deberá consumir con mayor sobriedad, es necesario abrir otras vías como, por ejemplo, formas de cooperación para las adquisiciones, como ocurre con las cooperativas de consumo, que existen desde el s. XIX, gracias también a la iniciativa de los católicos» (CV 66).

De las palabras del Papa se deduce que el estímulo del consumo requiere una actitud ética de educación para el consumo. El empresario sabe que ha de educar para consumir intentando controlar dicho consumo. Ya E. Weber propone varios objetivos de esta educación: orientación general sobre la economía de mercado, educación para el consumo racional, educación para una selección crítica y educación para el manejo racional de los recursos económicos y para el ahorro (Fraga, 1973). En una sociedad de mercado, en la que está situada toda empresa moderna, la producción en serie tiene su correlato consumista en serie. Poco a poco se va creando el tipo de hombre consumidor que pone su afán en tener más para consumir más.

La simbiosis entre sociedad de consumo y Estado asistencial crea estructuras que son de pecado porque impiden la plena realización de los que son oprimidos de diversas formas (Flecha, 1990). Demoler tales estructuras y sustituirlas por formas de convivencia más auténticas es una tarea que exige paciencia. Con el objeto de salir de este status consumista y de esa cultura de consumo se sugieren en la encíclica varias posibilidades de tipo cultural-práctico: dejarse llevar por una imagen integral del hombre que respete todas las dimensiones de su ser, oponerse a los hábitos de consumo, crear con urgencia una gran obra educativa y cultural que comprenda la educación de los consumidores para un uso responsable de su capacidad de elección, la formación de un profundo sentido de responsabilidad ante los productos y sobre todo con los profesionales (Centesimus annus, 36).

Los seguidores de la cultura desarrollista optan por el progreso ilimitado como un modo de vivir para la productividad y el consumismo, aunque con ello se expongan a hacer desaparecer algunas culturas y se organice la totalidad de la sociedad siguiendo esquemas propios de una sociedad tecnificada uniformemente que a medio o largo plazo produce una continua crisis económica (Galindo, 1996). 


\section{Conclusiones}

Después de esta reflexión, centrada en la lectura de CV y de la DSI, podemos llegar a algunas conclusiones en las que las tres lógicas -Estado, mercado y don- son comprendidas e interpretadas desde el binomio gratuidad y sociedad civil, base antropológica del ser humano como 'ser' social, creado gratuitamente:

$1^{\circ}$ ) Economía en una sociedad civil y participativa. Las Entidades no lucrativas son la estructura social de la solidaridad que además del valor moral supone para algunos un valor político que justifica y fundamenta diversos derechos. Lo importante es que asistimos a una explosión de la misma como consecuencia de la mayor participación que la sociedad civil adquiere dentro del Estado del Bienestar. Como afirma A. Schaff entre las fuerzas concurrentes en la construcción de un nuevo orden social no se puede infravalorar el potencial del cristianismo. Hoy se impone ir más allá del viejo marco del diálogo entre la las fuerzas políticas y el cristianismo. Se impone una colaboración concreta en la lucha por unos objetivos comunes (Schaff, 1993: 47). La colaboración adquiere una importancia decisiva en la lucha por un nuevo orden social.

$\left.2^{\circ}\right)$ Una economía a precio de gratuidad. Las nuevas ofertas de la encíclica quieren responder a las nuevas situaciones económicas que nacen de una Economía de globalización que no pretenden restaurar los antiguos sistemas económicos sino más bien situarse en otro paradigma, el del tercer sector y en la convivencia humana civil y sociedad participativa, para lo que, según la encíclica, es necesario iniciar diversos cambios.

$3^{\circ}$ ) Hacia una economía civil. La aportación de este estilo de economía gratuita, que nos recuerda la gratuidad del ejercicio de los diezmos y de la aportación del tercio de los producido de las órdenes religiosas medievales, nace del convencimiento de que la economía, tanto en sus aspectos teóricos como en los prácticos, necesita comprender el mundo social para contribuir a la construcción de una convivencia humana civil. Se trata de promover un tipo de economía empresarial tanto en su método como en sus fines, propiamente civil más que una ciencia o teoría especulativa y sistemática apta para políticos y economistas de oficio.

$\left.4^{\circ}\right)$ Un cambio de estilo interior. Sin lugar a dudas que estamos ante un proyecto que replantea la lógica del liberalismo, con su individualismo inherente, y del colectivismo con su manipulación alienante de la persona. En la época de la globalización, en la que el mercado con su regla de la ley del más fuerte conquista el mundo introduciendo nuevos procesos tanto económicos como sociales y culturales, nos encontramos en las propuestas de la encíclica con un radical cambio de estilo de vida y 
de actitudes mentales y morales. La filosofía que está en la base de este nuevo estilo se enfrenta al individualismo liberal que produce unos cambios éticos empobrecedores de la persona en su ámbito social.

$\left.5^{\circ}\right)$ La presencia de una ética no manipulable. Por ello, la presencia de la ética en la lógica del mercado y en la lógica del Estado resulta difícil pero posible y, por ello, se invita a participar a la sociedad civil bajo la lógica de la gratuidad. En este caso, las claves éticas deben fundarse en sus orígenes evangélicos si no queremos que las innovaciones tecnológicas, la técnica y la eficacia reduzcan todo a la dimensión utilitarista. Fundar la ética sobre la humanidad misma significa indicar qué valores universales deben ser subrayados para orientar el desarrollo integral y el progreso. En este horizonte del nuevo milenio, caracterizado por la globalización de todos los elementos de la vida humana, se requiere de una imaginación creativa, como esta encíclica pone en evidencia.

$\left.6^{\circ}\right)$ La búsqueda del bien común. En el campo empresarial, la encíclica además de proponer como objetivo y de buscar el Bien Común, en concreto intenta instaurar relaciones respetuosas, animadas de sincero espíritu de servicio y de colaboración, en las relaciones con los clientes, la administración pública y los competidores; busca valorar al máximo a los dependientes informándoles de los pasos diversos en la gestión; mantiene una línea de conducta de la empresa inspirada en la cultura de la legalidad; presta grandes atenciones a la ecología, al ambiente de trabajo y al cuidado de la naturaleza; promueve la colaboración con otras realidades sociales y económicas presentes en el territorio con los cuales se muestra solidaria sin olvidar la perspectiva y el horizonte universal.

$7^{\circ}$ ) Características de la lógica del don en la economía del tercer sector. Concretando nuestro discurso a la imagen que se viene dando últimamente al tercer sector, se puede incluir en este campo una economía generosa y solidaria, la gratuidad-generosidad humana manifestada desde la raíz de la caridad y los medios del don, donde la entrega y la comunión de bienes tienen más significación que el intercambio comercial, que el contrato mercantil y que la intervención estatal. Aquí puede situarse la, hoy llamada y ya extendida en la praxis, economía de comunión. En este ámbito del compromiso se insiste:

- En la prioridad de lo social sobre lo individual, y de los intereses colectivos (promovidos por el Estado o por los particulares) sobre el individualismo.

- En el contenido de una gratuidad que se hace sin la garantía de la recompensa o devolución. 
- En una organización social basada en un "vínculo social" o asociativa con una amplia participación y funcionamiento personalizado.

Esto porque la actividad en el tercer sector se aplica a la unidad de la dimensión económica y política de la vida humana, individual y social, con la insistencia puesta en la economía de servicios o que buscan la aportación económica para satisfacer las necesidades comunitarias, ya que en este campo la primera responsabilidad no es del Estado, sino de cada persona y de los diversos grupos y asociaciones en que se articula la sociedad (Centesimus annus, 48).

Hemos puesto, por tanto, en el centro de nuestro discurso el principio de gratuidad. En las actuales circunstancias históricas, el significado de las palabras independencia-pertenencia, libertad-justicia, eficiencia-equidad, don y gratuidad, e interés-solidaridad no implica necesariamente contradicción en sus términos. Es falso pensar que cualquier refuerzo del sentido de pertenencia implique una reducción de la independencia personal, o que cualquier avance en la eficiencia comporte una amenaza para la equidad y la autonomía, o que cualquier mejora de interés individual suponga un debilitamiento de la solidaridad.

\section{REFERENCIAS}

-Altaba, V. et al. (2009). Una lectura de Caritas in veritate desde Caritas. Corintios XIII (132), 175-194.

-Alves dos Santos, A. C. et al. (2010). Economia e vida na perspectiva da encíclica Caritas in veritate. São Paulo: Núcleo Fé e Cultura da PUC-SP.

-Arroyo, G. (1996). Globalización del capitalismo. ¿Quedan caminos para un desarrollo integral?, Persona y Sociedad, X (2), 11-28.

-Benedicto XVI (2009). Los Padres de la Iglesia. México: Buena Prensa.

-Bruni, L. y Zamagni, S. (2009). Persona y Comunión, herramientas para una refundación relacional del discurso económico. Buenos Aires: Ciudad Nueva.

-Camacho, I. (1998). Globalización, capitalismo y doctrina social de la Iglesia. Sociedad y utopia (12), 275-296.

-Cuesta, M. de la y Rodríguez, L. (Coords.) (2004). Responsabilidad social corporativa. Salamanca: UPSA.

-Cuesta, M. de la y Galindo, Á. (Coords.) (2005). Inversiones socialmente responsables. Salamanca: UPSA.

-Dijon, X. (2009). Le livre de la nature dans l'encyclique Caritas in veritate. Nowvelle Revue Théologique, 131 (4), 749-770.

-Flecha, J. R. (1990). La teología del desarrollo. Estructuras de pecado. En AA.VV., Comentarios a la Sollicitudo rei socialis (págs. 21-53). Madrid: ASE. 
-Fraga, M. (1973). Economía de consumo y sociedad: las críticas de Marcuse y otros contemporáneos. Anales de moral social y económica, 33, 63-79.

-Galindo, A. (1992). Propiedad privada y propiedad del saber. En AA. VV., Comentario a la Centesimus annus (págs. 189-226). Madrid: ASE.

-Galindo, A. (1996). Manual de Moral socioeconómica. Madrid: BAC.

-Galindo, A. (1998). Atención a pobres y desasistidos. Hacia una beneficencia socializada en la Segovia del siglo XV. En A. Galindo García (Ed.), Segovia en el siglo XV (págs. 469-494). Salamanca: UPSA.

-Galindo, A. (1999). El cristianismo ante el actual sistema económico mundial. En AA.VV., Las ideologías al final del siglo. Perspectivas desde el pensamiento cristiano (págs. 110-127). Salamanca: Ediciones Universidad.

-Galindo, A. (2001). ¿Globalización o mundialización? Sus implicaciones éticas. En AA. VV., La globalización y sus efectos en los inicios del tercer milenio. (págs. 129-150). Ávila: Universidad Católica de Ávila.

-Galindo, A. (2004). Nuevos ámbitos de responsabilidad social de la empresa. Desde el tercer sector a la economía de Comunión. Papeles de ética económica, economía y dirección (8), 151-172.

-Galindo, A. (2005a). La cooperación internacional para el desarrollo. En J. T. Raga (Coord.), Reflexiones para empresarios y directivos sobre el Compendio de Doctrina Social de la Iglesia (págs. 225-259). Madrid: ASE.

-Galindo, A. (2005b). La organización social de la Ciudad de Dios. Instituciones intermedias y estructuras políticas. Agustiniana, 46 (139), 5-43.

-Galindo, A. (2007a). Ética y economía. México: IMDOSOC.

-Galindo, A. (2007b). Ética social en los novohispanos. En I. Murillo (Coord.), El pensamiento bispánico en América: siglos XVI-XVII (págs. 571-598). Salamanca: UPSA.

-Herr, E. (2009). L'encyclique Caritas in veritate. Une lectura. Nouvelle Revue Théologique, 131 (4), 728-748.

-Ivern, A. (2004). Hacia una pedagogía de la reciprocidad. Buenos Aires: Ciudad Nueva.

-Lubich, Ch. (2003). Una lectura nueva para una nueva sociedad. Buenos Aires: Ciudad Nueva.

-Lubich, Ch. (2007). Economía de Comunión, bistoria y profecía. Buenos Aires: Ciudad Nueva.

-Martínez, J. L. (2010). Caritas in veritate. El desarrollo humano integral en tiempos de globalización y de crisis. Sal terrae, 98 (1141), 73-92.

-Muro, T. (2009). Substrato antropológico de la encíclica Caritas in veritate. Corintios XIII. Revista de Teología y pastoral de la caridad, 132, 22-44.

-Ruíz de la Peña, J. L. (1982). Las nuevas antropologías. Un reto a la teología. Santander: Sal Terrae.

-Schaff, A. (1993). Humanismo ecuménico. Madrid: Trotta. 
Sumario: 1. Planteamiento de la cuestión; 2. La lógica del Estado; 3. La lógica del mercado; 4. La lógica del Don; 4.1.; Antecedentes de la gratuidad en la vida económica; 4.2. La lógica del don en un mundo global; Conclusiones; Referencias. 